\title{
openheart Comparable effect of aliskiren or a diuretic added on an angiotensin II receptor blocker on augmentation index in hypertension: a multicentre, prospective, randomised study
}

Toru Miyoshi, ${ }^{1}$ Takashi Murakami, ${ }^{2}$ Satoru Sakuragi, ${ }^{3}$ Masayuki Doi, ${ }^{4}$ Seiji Nanba, ${ }^{5}$ Atsushi Mima, ${ }^{6}$ Youkou Tominaga, ${ }^{7}$ Takafumi Oka, ${ }^{8}$ Yutaka Kajikawa, ${ }^{9}$ Kazufumi Nakamura, ${ }^{1}$ Hiroshi Ito ${ }^{1}$

To cite: Miyoshi T, Murakami T, Sakuragi S, et al. Comparable effect of aliskiren or a diuretic added on an angiotensin II receptor blocker on augmentation index in hypertension: a multicentre, prospective, randomised study. Open Heart 2017;0:e000591. doi:10.1136/ openhrt-2017-000591

Received 10 January 2017 Revised 4 February 2017 Accepted 21 February 2017

CrossMark

For numbered affiliations see end of article.

Correspondence to Dr Toru Miyoshi; miyoshit@cc. okayama-u.ac.jp

\section{ABSTRACT}

Background The effects of antihypertensive drug combination therapy on central blood pressure (BP) and augmentation index (Al) have not been fully elucidated. We investigated the effects of the direct renin inhibitor, aliskiren, or a diuretic added to an angiotensin Il receptor blocker on Al in patients with essential hypertension.

Methods A 24-week, prospective, multicentre, randomised, open-label study enrolled 103 patients already treated with valsartan. Participants were randomly allocated to receive either valsartan with aliskiren $(\mathrm{V}+\mathrm{A})$, or valsartan with trichlormethiazide $(V+T)$. The primary outcome was the change in $\mathrm{Al}$ derived from radial artery tonometry. Secondary outcome measures included systolic and diastolic $\mathrm{BP}$, cardio-ankle vascular index (CAVI, which reflects arterial stiffness) and urinary 8-hydroxydeoxyguanosine concentration.

Results After 24 weeks, systolic and diastolic BP were significantly reduced in both groups to a broadly comparable extent. There was no significant difference in $\mathrm{Al}$ at the end of the study between the $\mathrm{V}+\mathrm{A}$ group and the $\mathrm{V}+\mathrm{T}$ group (between-group difference: $-2.3 \%$, $95 \% \mathrm{Cl}-6.9 \%$ to $2.2 \%, \mathrm{p}=0.31$ ). Central BP at the end of the study also did not differ between the two groups $(p=0.62)$. There was no significant difference in the CAVI between the groups at the end of the study. Urinary 8-hydroxydeoxyguanosine concentration was significantly lower in the $\mathrm{V}+\mathrm{A}$ group than in the $\mathrm{V}+\mathrm{T}$ group $(\mathrm{p}<0.01)$, suggesting that $\mathrm{V}+\mathrm{A}$ attenuated oxidative stress more than $\mathrm{V}+\mathrm{T}$.

Conclusion The combination of valsartan and aliskiren had an effect on Al comparable with that of the combination of valsartan and trichlormethiazide. UMIN Clinical Trial Registration number UMIN000005726.

\section{INTRODUCTION}

The pulse wave is reflected back from regions of impedance mismatch in the arterial tree. ${ }^{2}$ The augmentation index (AI), determined

\section{KEY QUESTIONS}

What is already known about this subject?

- Augmentation index (Al) and central haemodynamics were reported to be associated with cardiovascular structural damage and clinical outcomes. Different classes of antihypertensive drugs have different effects on Al and central aortic pressures.

What does this study add?

- A 24-week, prospective, multicentre, randomised, open-label study demonstrated that treatment of valsartan with aliskiren, or valsartan with trichlormethiazide, decreased Al and central pressure similarly. Urinary 8-hydroxydeoxyguanosine concentration was significantly lower in the valsartan with aliskiren group than in the valsartan with trichlormethiazide group, suggesting that valsartan with aliskiren attenuated oxidative stress more than valsartan with trichlormethiazide.

How might this impact on clinical practice?

- The combination of valsartan and aliskiren did not show better effect on central haemodynamics than the combination of valsartan and trichlormethiazide.

from the central arterial pressure waveform, has been proposed as a measure of aortic stiffness and wave reflection. ${ }^{1} \mathrm{AI}$ is the proportion of central pulse pressure attributable to the secondary systolic pressure rise produced by the overlap of forward and reflected pressure waves. The AI derived from the radial pulse waveform has been demonstrated to correlate well with the AI in the aortic pressure waveform. ${ }^{3}$ Several studies have illuminated the relationships among AI, cardiovascular structural damage and clinical outcomes. ${ }^{45}$ 


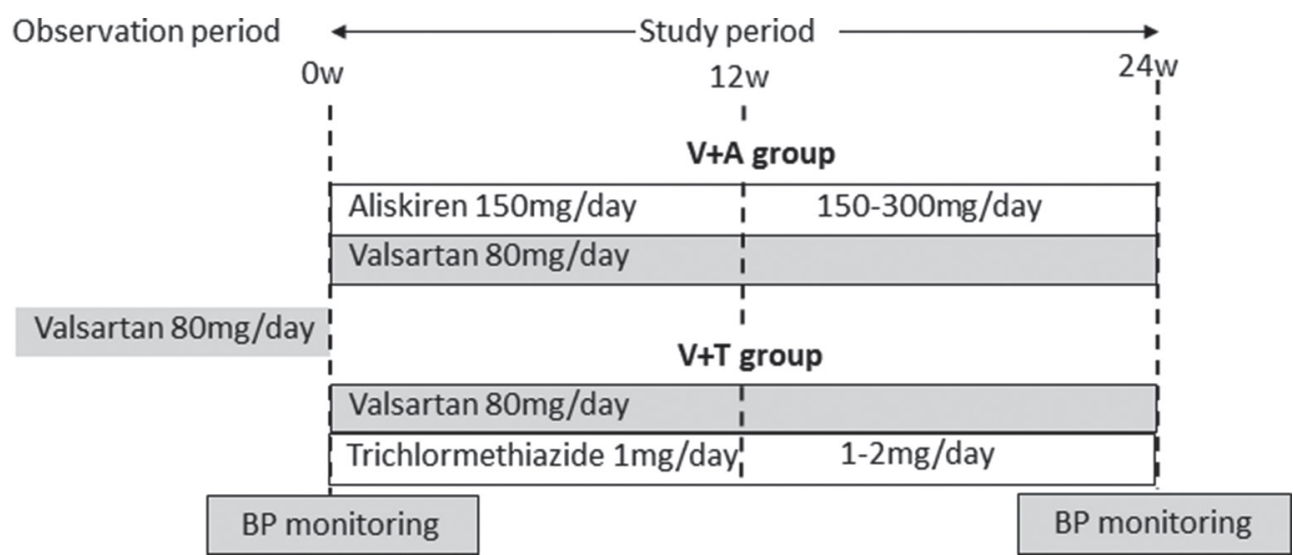

Figure 1 Study protocol. Patients were randomly assigned to either the valsartan with aliskiren $(V+A)$ group or the valsartan with trichlormethiazide $(\mathrm{V}+\mathrm{T})$ group. Both groups were given valsartan $80 \mathrm{mg} /$ day, in combination with aliskiren $150 \mathrm{mg} /$ day in the $\mathrm{V}+\mathrm{A}$ group or $1 \mathrm{mg} /$ day trichlormethiazide in the $\mathrm{V}+\mathrm{T}$ group. After 12 weeks, dose titration was permitted up to $300 \mathrm{mg} /$ day aliskiren or $2 \mathrm{mg} /$ day trichlormethiazide. Treatment was continued for a further 12 weeks. BP, blood pressure.

Different classes of antihypertensive drugs have different effects on $\mathrm{AI}$ and central aortic pressures, even if they have a similar impact on brachial blood pressure (BP). Several studies have demonstrated that, in monotherapy, the effects of an ACE inhibitor or calcium channel blocker (CCB) on AI were greater than those of a -adrenoreceptor blocker or a diuretic. ${ }^{67}$ There have also been several reports on the effect of combination antihypertensive therapy on AI. The Conduit Artery Function Evaluation study demonstrated that CCB-based therapy had a greater effect on central aortic pressure and AI than $\beta$-blocker-based therapy. ${ }^{4}$ Another study reported that the effects of a combination of an angiotensin II type 1 receptor blocker (ARB) and a CCB on AI were greater than that of an ARB and a diuretic. ${ }^{89}$ Aliskiren, an orally available non-peptide renin inhibitor, blocks the renin-angiotensin system (RAS) by reducing the production of angiotensin. ${ }^{10}$ However, the effects of combination therapy with aliskiren and other antihypertensive drugs on AI and central aortic pressure are not known.

The aim of this study was to investigate whether aliskiren or a diuretic added to valsartan, an ARB, reduced AI in patients with essential hypertension inadequately treated with valsartan alone.

\section{METHODS}

\section{Study population}

This was a 24-week, prospective, multicentre, open-label, randomised study. Participants were enrolled at the 12 affiliated hospitals of Okayama University in Japan from June 2012 to March 2013. Conduct of the study was approved by the ethics committees of Okayama University and other hospitals. All participants provided written informed consent before enrolment. This study was conducted according to the principles expressed in the Declaration of Helsinki.

Eligible patients were adults ( $>30$ and $<85$ years old) with essential hypertension who had not achieved a
BP goal of 140/90 mm $\mathrm{Hg}$ after receiving ARB monotherapy. Patients with the following conditions were excluded: renal insufficiency (serum creatine concentration $\geq 2 \mathrm{mg} / \mathrm{dL}$ ), secondary hypertension, severe hypertension (systolic BP $\geq 180 \mathrm{~mm} \mathrm{Hg}$ or diastolic $\mathrm{BP} \geq 110 \mathrm{~mm} \mathrm{Hg}$ ), congestive heart failure (New York Heart Association class II or greater), severe valvular heart disease, myocardial infarction or stroke within 6 months of study initiation, chronic atrial filtration, malignant arrhythmia, severe liver disease, chronic inflammatory disease, malignant disease (expected survival $<6$ months) or treatment with a RAS inhibitor other than an ARB.

\section{Study design}

The study design is shown in figure 1. Patients were randomly assigned to either the valsartan with aliskiren $(\mathrm{V}+\mathrm{A})$ group or the valsartan with trichlormethiazide $(\mathrm{V}+\mathrm{T})$ group. Randomisation was conducted by the clinical trials unit based at Okayama University via a secure website and was stratified by the centre using random permuted blocks. Both groups were given valsartan $80 \mathrm{mg} /$ day, in combination with aliskiren $150 \mathrm{mg} /$ day in the $\mathrm{V}+\mathrm{A}$ group or $1 \mathrm{mg} /$ day trichlormethiazide in the $\mathrm{V}+\mathrm{T}$ group. After 12 weeks, dose titration was permitted up to $300 \mathrm{mg} /$ day aliskiren or $2 \mathrm{mg} /$ day trichlormethiazide if BP had not been lowered to the extent recommended in the 2009 Japanese Society of Hypertension guidelines. ${ }^{11}$ Treatment was continued for a further 12 weeks. Other drugs that could potentially have interfered with the efficacy of the study drugs were prohibited.

\section{End points}

The primary outcomes were the change in the radial AI and central BP. To avoid multiplicity issue, we prioritised AI. The secondary outcomes were arterial BP, the change in arterial stiffness and serum and urine biochemical parameters. 


\section{Data collection}

BP and pulse wave analysis

First, after a 5 mins rest and with the subject seated, brachial BP was measured using an automatic cuff oscillometric device. The mean of two readings was used to determine systolic BP, diastolic BP, mean arterial pressure and pulse pressure. ${ }^{9} \mathrm{Next}$, the radial pulse wave was determined at the wrist using applanation tonometry with a high-fidelity micromanometer (HEM-9000AI; Omron Healthcare, Kyoto, Japan), as previously described.12 13 The AI of the radial pulse was calculated as the difference between the first systolic peak and the second systolic peak (reflection wave) of the pulse waveform, expressed as a percentage of the second peak relative to the first peak. The estimated central BP and heart rate-corrected AI (AI@75, the AI adjusted to the heart rate of 75 beats per minute) were derived from the HEM-9000AI.

\section{Arterial stiffness}

To assess arterial stiffness, the cardio-ankle vascular index (CAVI) was measured automatically using a VaSera device (Fukuda Denshi, Tokyo, Japan), informed by recordings of the BP, pulse wave velocity (PWV), ECG and heart sounds..$^{14}$ The PWV was calculated by dividing the distance from the aortic valve to the ankle artery by the sum of the time between the aortic valve closing sound and the notch of the brachial pulse wave, and the time between the rise of the brachial pulse wave and the ankle pulse wave. The CAVI was determined using the following equation: CAVI $=\mathrm{a}[(2 \rho / \Delta \mathrm{P}) \times \ln (\mathrm{Ps} / \mathrm{Pd}) \times \mathrm{PWV} 2]+\mathrm{b}$, where Ps and $\mathrm{Pd}$ are the systolic and diastolic $\mathrm{BP}$, respectively; $\mathrm{PWV}$ is the $\mathrm{PWV}$ between the heart and ankle; $\Delta \mathrm{P}$ is $\mathrm{Ps}-\mathrm{Pd} ; \rho$ is the blood density and $\mathrm{a}$ and $\mathrm{b}$ are constants. ${ }^{15}$ The mean of the CAVI measured on each side was used for analysis.

\section{Blood sampling}

Blood samples were collected from an antecubital vein after 12 hours of overnight fast and after at least $30 \mathrm{~min}$ of rest with the patient in supine position. Routine haematology and biochemistry, including glycated haemoglobin (HbA1c), and the serum concentrations of total cholesterol, high-density lipoprotein (HDL) cholesterol, low-density lipoprotein (LDL) cholesterol, triglycerides, creatine $(\mathrm{Cr})$ and uric acid were measured immediately using an autoanalyser. The serum concentrations of aldosterone, brain natriuretic peptide (BNP) and adiponectin, and the urinary concentration of 8-hydroxydeoxyguanosine, were measured at a single institution (SRL Hachioji Laboratory, Tokyo, Japan). We calculated the 8-hydroxydeoxyguanosine to creatine (8-OHdG/Cr) and urinary albumin to creatine (UACR) ratios. The estimated glomerular filtration rate (eGFR) was calculated by the following equation: eGFR (mL/ $\left.\min / 1.73 \mathrm{~m}^{2}\right)=194 \times \mathrm{Cr}^{-1.094} \times$ age $^{-0.287} \times(0.739$ if female $) .{ }^{16}$ Chronic kidney disease was defined as an eGFR $<60 \mathrm{~mL} /$ $\mathrm{min} / 1.73 \mathrm{~m}^{2}$. The study investigators who collected and analysed the data were blinded to the participants' randomisation status.

\section{Statistical analysis}

The sample size was determined on the basis of the estimated AI reported in other recent studies. ${ }^{4917} \mathrm{We}$ assumed a mean difference in $\mathrm{AI}$ of $3.5 \%$, with an $\mathrm{SD}$ of $7 \%$. Using a two-sided test for differences, a minimum sample size of 64 patients was required in each group to detect statistically significant differences in AI with a power of $80 \%$ and an $\alpha$-type error of $5 \%$.

Data are presented as the mean $\pm \mathrm{SD}$ unless otherwise stated. The unpaired Student's t-test was used for comparisons of continuous variables between groups. Categorical variables were compared between groups by $\chi^{2}$ analysis. The paired Student's t-test was used to compare changes in continuous variables in a group from baseline to the end of the study. Analysis of covariance (ANCOVA) was performed to compare the haemodynamic and biochemical parameters between the groups with age, sex and each baseline covariate, as the mean of age of the groups stratified by sex was slightly different (data not shown). The least squares mean and 95\% CI for between-treatment group differences were also calculated. Values of $\mathrm{p}<0.05$ were considered statistically significant. Data were analysed using SPSS 17.0 for Windows V.24.

\section{RESULTS \\ Participants}

We randomised 103 participants to the $\mathrm{V}+\mathrm{A}$ and $\mathrm{V}+\mathrm{T}$ groups (figure 2), but the data of 97 were subject to final analysis (48 in the $\mathrm{V}+\mathrm{A}$ group and 49 in the $\mathrm{V}+\mathrm{T}$ group). There were no significant differences in age, sex, height, body mass index, smoking status or baseline drug regime of each group (table 1). Patients with chronic kidney disease comprised $60 \%$ of the $\mathrm{V}+\mathrm{A}$ group and $59 \%$ of the $\mathrm{V}+\mathrm{T}$ group. The mean eGFR in the $\mathrm{V}+\mathrm{A}$ group and the $\mathrm{V}+\mathrm{T}$ group was $56.3 \pm 13.2 \mathrm{~mL} / \mathrm{min} / 1.73 \mathrm{~m}^{2}$ and $57.8 \pm 18.0 \mathrm{~mL} / \mathrm{min} / 1.73 \mathrm{~m}^{2}$, respectively. The mean final doses of aliskiren and trichlormethiazide were $198.8 \pm 71.1 \mathrm{mg} /$ day and $1.5 \pm 0.7 \mathrm{mg} /$ day, respectively.

\section{Changes in haemodynamic parameters}

The changes in the haemodynamic parameters in each group over the study period are shown in table 2. Systolic and diastolic BPs were significantly lower in both groups at the end of the study and to a broadly comparable extent. The AI at the end of the study in the $\mathrm{V}+\mathrm{A}$ group was significantly lower than baseline $(p=0.01)$, but there was no significant change in the $\mathrm{V}+\mathrm{T}$ group over the course of the study $(\mathrm{p}=0.06)$; there was no significant difference in the AI at the end of the study between the groups $(\mathrm{p}=0.31)$. Change in AI was associated with change in $\mathrm{BP}$ in the $\mathrm{V}+\mathrm{A}$ group $(\mathrm{r}=0.52, \mathrm{p}<0.01)$ and the $\mathrm{V}+\mathrm{T}$ group $(\mathrm{r}=0.56, \mathrm{p}<0.01)$. The AI@75 and central BP also decreased significantly from baseline over the course of the study in the $\mathrm{V}+\mathrm{A}$ and $\mathrm{V}+\mathrm{T}$ groups $(\mathrm{p}=0.01$ and $<0.01$, respectively), but there were no difference in the $\mathrm{AI} @ 75$ at the end of the study between the groups $(\mathrm{p}=0.46)$. Heart rate did not change significantly from baseline in 


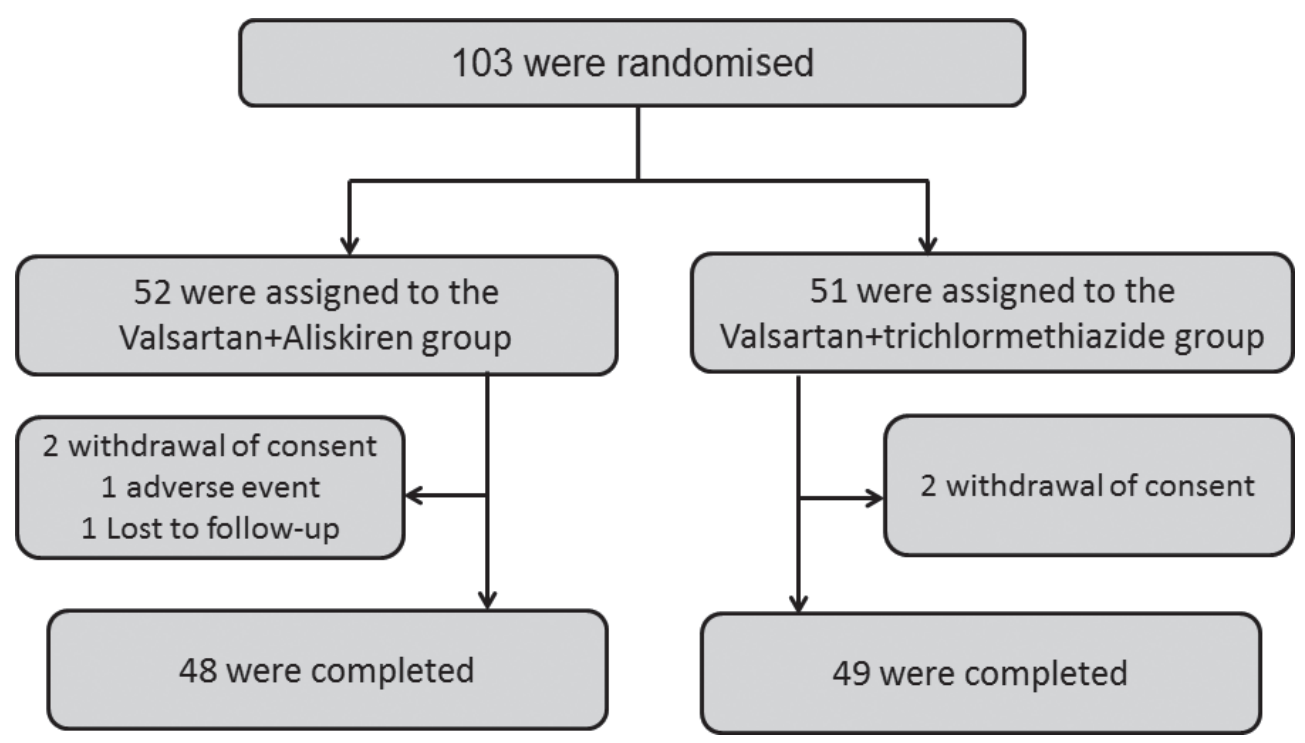

Figure 2 Patient distribution. A total of 103 participants were randomised into the $V+A$ and $V+T$ groups, but the data of 97 were subject to final analysis (48 in the $V+A$ group and 49 in the $V+T$ group). $V+A$, valsartan with aliskiren; $V+T$, valsartan with trichlormethiazide.

either the $\mathrm{V}+\mathrm{A}$ or $\mathrm{V}+\mathrm{T}$ group $(\mathrm{p}=0.93$ and 0.23 , respectively).

\section{Changes in biochemical parameters}

The changes in renal function, glucose metabolism, lipid profiles and other biochemical parameters over the course of the study are shown in table 3. At the end of the study, serum creatine concentration was significantly elevated from baseline in the $\mathrm{V}+\mathrm{T}$ group $(\mathrm{p}=0.02)$, but there was no significant difference in serum creatine concentration between the groups at the end of the study $(\mathrm{p}=0.36)$. No increase in serum potassium concentration was evident in either group. The UACR was significantly

\begin{tabular}{|c|c|c|}
\hline & $\begin{array}{l}V+A \text { group } \\
(n=48)\end{array}$ & $\begin{array}{l}V+T \text { group } \\
(n=49)\end{array}$ \\
\hline Age (years) & $68 \pm 10$ & $68 \pm 10$ \\
\hline Men & $21(44)$ & $21(43)$ \\
\hline Body height (cm) & $156.0 \pm 10.0$ & $156.9 \pm 8.1$ \\
\hline $\mathrm{BMI}\left(\mathrm{kg} / \mathrm{m}^{2}\right)$ & $24.9 \pm 3.8$ & $24.7 \pm 3.6$ \\
\hline Dyslipidaemia & $21(44)$ & $22(44)$ \\
\hline Diabetes mellitus & $7(14)$ & $4(8)$ \\
\hline Chronic kidney disease & $29(60)$ & $29(59)$ \\
\hline Current smoking & $10(21)$ & $6(12)$ \\
\hline Previous CVD & $10(21)$ & $10(20)$ \\
\hline Hypoglycaemic drugs & $7(14)$ & $2(4)$ \\
\hline Statins & $16(33)$ & $15(31)$ \\
\hline
\end{tabular}

Data are expressed as the mean $\pm S D$ or the number (percentage). $\mathrm{BMI}$, body mass index; CVD, cardiovascular disease; $\mathrm{V}+\mathrm{A}$, valsartan with aliskiren; $\mathrm{V}+\mathrm{T}$, valsartan with trichlormethiazide. reduced in both groups after treatment $(\mathrm{V}+\mathrm{A}$ group, $\mathrm{p}=0.001 ; \mathrm{V}+\mathrm{T}$ group, $\mathrm{p}=0.02)$, but the extent of reduction did not differ between the groups $(p=0.06)$. The HbA1c at the end of the study was significantly lower in the $\mathrm{V}+\mathrm{A}$ group than in the $\mathrm{V}+\mathrm{T}$ group $(\mathrm{p}<0.01)$. The serum concentrations of LDL cholesterol, triglyceride and HDL cholesterol in both groups did not change significantly over the course of the study. The serum uric acid concentration in the $\mathrm{V}+\mathrm{T}$ group was significantly higher at the end of the study than in the $\mathrm{V}+\mathrm{A}$ group $(\mathrm{p}<0.01)$, but there were no significant changes in the serum concentrations of aldosterone, adiponectin, BNP and urinary creatine. The urinary $8-\mathrm{OHdG} / \mathrm{Cr}$ ratio exhibited a significantly greater reduction in the $\mathrm{V}+\mathrm{A}$ group than in the $\mathrm{V}+\mathrm{T}$ group $(\mathrm{p}<0.01)$. Plasma renin activity in the $\mathrm{V}+\mathrm{A}$ group was significantly reduced more than that in the $\mathrm{V}+\mathrm{T}$ group $(\mathrm{p}<0.01)$. In all patients, the change in plasma renin activity was significantly correlated with the change in the urinary $8-\mathrm{OHdG} / \mathrm{Cr}$ ratio $(\mathrm{r}=0.29, \mathrm{p}<0.01)$.

\section{Change in arterial stiffness}

The CAVI was significantly reduced in both groups after 24 weeks of treatment (falling from $9.0 \pm 1.5$ to $8.6 \pm 1.3$ in the $\mathrm{V}+\mathrm{A}$ group, $\mathrm{p}=0.01$; and from $8.8 \pm 1.2$ to $8.5 \pm 1.2$ in the $\mathrm{V}+\mathrm{T}$ group, $\mathrm{p}=0.02)$. At the end of the study, there was no significant difference in CAVI between the groups (mean 8.55 (95\% CI 9.29 to 9.29 ) in the $\mathrm{V}+\mathrm{A}$ group compared with 8.54 (95\% CI 8.28 to 8.79 ) in the $\mathrm{V}+\mathrm{T}$ group; $\mathrm{p}=0.97$ by ANCOVA).

\section{Safety analysis}

One patient in the $\mathrm{V}+\mathrm{A}$ group discontinued the study because of hypotension. There were no other reports of adverse events, such as hyperkalaemia, oedema, diarrhoea or renal impairment. 
Table 2 Adjusted changes in haemodynamic parameters in the $\mathrm{V}+\mathrm{A}$ and in the $\mathrm{V}+\mathrm{T}$ groups

\begin{tabular}{|c|c|c|c|c|c|}
\hline & & $V+A$ group $(n=48)$ & $V+T$ group $(n=49)$ & $\begin{array}{l}\text { Between-group } \\
\text { difference }\end{array}$ & $\mathbf{p}$ \\
\hline SBP & Baseline & $155 \pm 16$ & $155 \pm 17$ & & \\
\hline \multirow[t]{2}{*}{$(\mathrm{mm} \mathrm{Hg})$} & End of study & $137 \pm 21^{*}$ & $138 \pm 16^{*}$ & & \\
\hline & End of study ${ }^{\dagger}$ & $138>(132$ to 143$)$ & 138 (133 to 143$)$ & -0.7 ( -7.9 to 6.5$)$ & 0.85 \\
\hline DBP & Baseline & $88 \pm 11$ & $88 \pm 12$ & & \\
\hline \multirow[t]{2}{*}{ (mm Hg) } & End of study & $79 \pm 13^{*}$ & $80 \pm 12^{*}$ & & \\
\hline & End of study ${ }^{\dagger}$ & 79 (76 to 82) & 81 (77 to 84) & $-1.5(-5.9$ to 3.0$)$ & 0.52 \\
\hline Heart rate & Baseline & $69 \pm 10$ & $70 \pm 11$ & & \\
\hline \multirow[t]{2}{*}{ (bpm) } & End of study & $69 \pm 14$ & $68 \pm 11$ & & \\
\hline & End of study ${ }^{\dagger}$ & 69 (67 to 72$)$ & 68 (68 to 69$)$ & $1.6(-2.6$ to 5.7$)$ & 0.45 \\
\hline $\mathrm{Al}$ & Baseline & $92.5 \pm 11.7$ & $91.8 \pm 13.0$ & & \\
\hline \multirow[t]{2}{*}{$(\%)$} & End of study & $87.3 \pm 15.9^{*}$ & $88.7 \pm 13.1$ & & \\
\hline & End of study ${ }^{\dagger}$ & 86.2 (83.0 to 89.4) & 88.5 (85.3 to 91.7) & $-2.3(2.2$ to 6.9$)$ & 0.31 \\
\hline Al@75 & Baseline & $87.2 \pm 12.1$ & $89.8 \pm 11.0$ & & \\
\hline \multirow[t]{2}{*}{$(\%)$} & End of study & $82.2 \pm 17.9^{*}$ & $85.8 \pm 11.2^{*}$ & & \\
\hline & End of study ${ }^{\dagger}$ & 83.8 (80.8 to 86.9 ) & 85.5 (82.4 to 88.5) & $-1.6(-6.0$ to 2.7$)$ & 0.46 \\
\hline Central BP & Baseline & $162 \pm 24$ & $164 \pm 21$ & & \\
\hline \multirow[t]{2}{*}{$(\mathrm{mm} \mathrm{Hg})$} & End of study & $145 \pm 26^{*}$ & $149 \pm 24^{*}$ & & \\
\hline & End of study ${ }^{\dagger}$ & 147 (140 to 153$)$ & 149 (143 to 155$)$ & $-2.2(-11.2$ to 6.7$)$ & 0.62 \\
\hline
\end{tabular}

Data are expressed as the mean \pm SD or mean $(95 \% \mathrm{Cl})$.

${ }^{*} p<0.01$ versus baseline (paired t-test) and ${ }^{* *} p<0.05$ versus baseline (paired t-test).

†The least square means $(95 \% \mathrm{Cl})$ and $\mathrm{p}$ values were derived from ANCOVA adjusted for age, sex and each baseline value.

ANCOVA, analysis of covariance; Al, augmentation index; AI@75, Al adjusted for a heart rate of 75 beats per minute; BP, blood pressure;

DBP, diastolic blood pressure; SBP, systolic blood pressure; $V+A$, valsartan with aliskiren; $V+T$, valsartan with trichlormethiazide.

\section{DISCUSSION}

We found that adding aliskiren to valsartan therapy reduced AI over a 24-week treatment period. Each combination reduced $\mathrm{AI}$ to a broadly comparable extent, but the reduction in urinary $8-\mathrm{OHdG} / \mathrm{Cr}$ ratio was greater in those taking valsartan with aliskiren. To the best of our knowledge, ours is the first study to have evaluated the effect of aliskiren-ARB combination therapy on AI and central BP. Our findings suggest that combination therapy with aliskiren and an ARB may have a similar effect on central haemodynamic parameters, but are more effective at treating systemic oxidative stress than a combination of a diuretic with an ARB in patients with hypertension.

Antihypertensive drugs can have different effects on AI and central aortic pressures despite a similar impact on brachial BP. ${ }^{6-8}$ Our previous study showed the effect of a combination of an ARB and a CCB on AI was greater than that of an ARB and a diuretic. ${ }^{9}$ In this study, dual RAS blockade with a direct renin inhibitor and an ARB was not able to show greater decrease in AI and central $\mathrm{BP}$ more than a combination of a diuretic and an ARB. Aliskiren suppresses the stimulation of the angiotensin II type 2 receptor, rather than blocking it like an $\mathrm{ARB},{ }^{18}$ and downregulates the ACE2/angiotensin-(1-7)/Mas receptor axis by inhibiting the upstream component of RAS. ${ }^{19}$ The beneficial effect of stimulating the angiotensin
II type 2 receptor, such as vasodilatory, anti-inflammatory and antifibrotic effects, may therefore be attenuated by aliskiren. As the reduction of CAVI was similar in both groups in this study, a combination of aliskiren and an ARB may not exhibit a superior vascular protective effect than a combination of a diuretic and an ARB.

We also demonstrated that the combination of aliskiren and valsartan reduced urine $8-\mathrm{OHdG} / \mathrm{Cr}$ ratio, a marker of oxidative stress, more than the combination of trichlormethiazide and valsartan. Other groups have reported that aliskiren attenuates oxidative stress in patients with diabetes mellitus, in non-diabetic patients and in patients with chronic kidney disease. ${ }^{2021}$ Oxidative stress is one of the most important influences on vascular remodelling. In this study, we chose a 6-month duration of therapy on the basis of prior experience. ${ }^{89} \mathrm{~A}$ longer duration of follow-up might have elicited a statistically significant therapeutic influence on arterial stiffness.

We also found that the combination of aliskiren and valsartan reduced UACR to a broadly comparable extent with the combination of trichlormethiazide and valsartan. There are limited data regarding the effect of combination therapy with aliskiren and other antihypertensive drugs on renal function. In line with our study, Abe and colleagues reported that a combination of aliskiren and telmisartan reduced the proportional 
Table 3 Adjusted changes in biochemical parameters in the $\mathrm{V}+\mathrm{A}$ and in the $\mathrm{V}+\mathrm{T}$ groups

\begin{tabular}{|c|c|c|c|c|c|}
\hline & & V+A group $(n=48)$ & V+T group $(n=49)$ & Between-group difference & $\mathbf{p}$ \\
\hline BUN & Baseline & $15.6 \pm 4.1$ & $16.2 \pm 4.2$ & & \\
\hline \multirow[t]{2}{*}{$(\mathrm{mg} / \mathrm{dL})$} & End of study & $17.5 \pm 5.2^{*}$ & $16.7 \pm 5.3$ & & \\
\hline & End of study* & 17.8 (16.6 to 19.0$)$ & $16.5(15.3$ to 17.7$)$ & $1.3(-0.46$ to 3.00$)$ & 0.15 \\
\hline Creatine & Baseline & $0.74 \pm 0.19$ & $0.74 \pm 0.22$ & & \\
\hline \multirow[t]{2}{*}{$(\mathrm{mg} / \mathrm{dL})$} & End of study & $0.76 \pm 0.20$ & $0.78 \pm 0.24^{*}$ & & \\
\hline & End of study* & 0.76 (0.74 to 0.79$)$ & 0.78 (0.76 to 0.81$)$ & $0.02(-0.02$ to 0.05$)$ & 0.36 \\
\hline $\mathrm{Na}$ & Baseline & $141.0 \pm 2.1$ & $141.5 \pm 2.1$ & & \\
\hline \multirow[t]{2}{*}{$(\mathrm{mEq} / \mathrm{L})$} & End of study & $140.6 \pm 2.2$ & $141.5 \pm 1.9$ & & \\
\hline & End of study* & $140.1(140.2$ to 141.3$)$ & $141.4(140.9$ to 141.9$)$ & $-0.6(-1.3$ to 0.10$)$ & 0.09 \\
\hline $\mathrm{K}$ & Baseline & $4.2 \pm 0.4$ & $4.2 \pm 0.3$ & & \\
\hline \multirow[t]{2}{*}{$(\mathrm{mEq} / \mathrm{L})$} & End of study & $4.3 \pm 0.4$ & $4.2 \pm 0.4$ & & \\
\hline & End of study* & $4.3(4.2$ to 4.4$)$ & $4.2(4.1$ to 4.3$)$ & $0.1(-0.9$ to 2.2$)$ & 0.40 \\
\hline $\mathrm{Cl}$ & Baseline & $104.5 \pm 2.1$ & $105.2 \pm 2.4$ & & \\
\hline \multirow[t]{2}{*}{$(\mathrm{mEq} / \mathrm{L})$} & End of study & $104.8 \pm 2.4$ & $105.3 \pm 2.3$ & & \\
\hline & End of study* & $105.0(104.5$ to 105.7$)$ & 105.1 (104.6 to 105.7$)$ & $-0.1(-0.9$ to 0.8$)$ & 0.89 \\
\hline UACR & Baseline & $35.9 \pm 38.9$ & $33.6 \pm 35.3$ & & \\
\hline \multirow[t]{2}{*}{ (mg/g creatine) } & End of study & $19.8 \pm 15.4^{\star}$ & $25.6 \pm 27.4^{\star}$ & & \\
\hline & End of study* & 19.2 (14.2 to 24.2$)$ & 26.0 (21.3 to 30.7 ) & $-6.7(-13.7$ to 0.14$)$ & 0.055 \\
\hline HbA1c & Baseline & $5.5 \pm 0.6$ & $5.3 \pm 0.3$ & & \\
\hline \multirow[t]{2}{*}{$(\%)$} & End of study & $5.5 \pm 0.6$ & $5.5 \pm 0.4^{\star \dagger}$ & & \\
\hline & End of study* & 5.5 (5.4 to 5.6$)$ & 5.7 (5.5 to 5.8$)$ & $-0.2(-0.3$ to -0.003$)$ & 0.045 \\
\hline LDL-C & Baseline & $129 \pm 58$ & $106 \pm 34$ & & \\
\hline \multirow[t]{2}{*}{$(\mathrm{mg} / \mathrm{dL})$} & End of study & $101 \pm 28$ & $106 \pm 33$ & & \\
\hline & End of study* & 102 (96 to 108$)$ & 106 (100 to 112) & $-4(-13$ to 5$)$ & 0.38 \\
\hline Triglyceride & Baseline & $130 \pm 59$ & $130 \pm 73$ & & \\
\hline \multirow[t]{2}{*}{ (mg/dL) } & End of study & $131 \pm 67$ & $129 \pm 69$ & & \\
\hline & End of study* & 131 (117 to 147$)$ & 129 (114 to 144$)$ & $3(-19$ to -24$)$ & 0.79 \\
\hline HDL-C & Baseline & $61 \pm 16$ & $61 \pm 15$ & & \\
\hline \multirow[t]{2}{*}{$(\mathrm{mg} / \mathrm{dL})$} & End of study & $62 \pm 18$ & $62 \pm 16$ & & \\
\hline & End of study* & 62 (59 to 65) & 62 (59 to 65) & $0.02(-3.8$ to -3.9$)$ & 0.99 \\
\hline Uric acid & Baseline & $4.7 \pm 1.3$ & $5.4 \pm 1.3$ & & \\
\hline \multirow[t]{2}{*}{$(\mathrm{mg} / \mathrm{nL})$} & End of study & $5.0 \pm 1.2$ & $5.7 \pm 1.3^{\star}$ & & \\
\hline & End of study* & $5.3(4.9$ to 5.7$)$ & 6.0 (5.7 to 6.4$)$ & $-0.7(-1.3$ to -0.2$)$ & $<0.01$ \\
\hline Plasma renin activity & Baseline & $2.1 \pm 2.5$ & $2.0 \pm 3.1$ & & \\
\hline \multirow[t]{2}{*}{ (ng/mL/hour) } & End of study & $0.7 \pm 1.0$ & $2.3 \pm 2.5$ & & \\
\hline & End of study* & 0.7 (0.2 to 1.2$)$ & 2.4 (1.9 to 2.9$)$ & $1.7(2.4$ to 1.0$)$ & $<0.01$ \\
\hline Aldosterone & Baseline & $79.4 \pm 43.7$ & $79.9 \pm 35.8$ & & \\
\hline \multirow[t]{2}{*}{$(\mathrm{pg} / \mathrm{mL})$} & End of study & $76.7 \pm 35.7$ & $79.7 \pm 33.1$ & & \\
\hline & End of study* & 75.8 (67.5 to 84.1$)$ & 81.3 (73.5 to 89.0$)$ & $-5.5(-16.8$ to 5.9$)$ & 0.34 \\
\hline Adiponectin & Baseline & $13.9 \pm 8.5$ & $13.8 \pm 8.9$ & & \\
\hline \multirow[t]{2}{*}{$(\mu \mathrm{g} / \mathrm{mL})$} & End of study & $14.2 \pm 7.9$ & $13.6 \pm 7.9$ & & \\
\hline & End of study* & 13.6 (12.9 to 14.4$)$ & $13.2(12.5$ to 13.9$)$ & $0.46(-0.56$ to 1.49$)$ & 0.37 \\
\hline BNP & Baseline & $48.8 \pm 53.0$ & $39.1 \pm 33.7$ & & \\
\hline \multirow[t]{2}{*}{ (ng/mL) } & End of study & $34.2 \pm 82.2$ & $27.8 \pm 53.6$ & & \\
\hline & End of study* & 32.5 (26.2 to 38.8 ) & 29.4 (23.2 to 35.5$)$ & $3.0(-5.7$ to 11.8$)$ & 0.49 \\
\hline
\end{tabular}


Table 3 Continued

\begin{tabular}{|c|c|c|c|c|c|}
\hline & & V+A group $(n=48)$ & $V+T$ group $(n=49)$ & Between-group difference & $\mathbf{p}$ \\
\hline (ng/mg creatine) & End of study & $10.3 \pm 3.9^{*}$ & $12.4 \pm 5.6$ & & \\
\hline Urinary creatine & Baseline & $0.87 \pm 0.50$ & $0.87 \pm 0.40$ & & \\
\hline$(\mathrm{mg} / \mathrm{dL})$ & End of study & $0.97 \pm 0.56$ & $1.04 \pm 0.82$ & & \\
\hline
\end{tabular}

Data are expressed as the mean \pm SD or mean $(95 \% \mathrm{Cl})$.

*The least square means $(95 \% \mathrm{Cl})$ and $p$ values were derived from ANCOVA adjusted for age, sex and each baseline value. tp $<0.01$ versus baseline (paired t-test) and ${ }^{* *} p<0.05$ versus baseline (paired t-test).

ANCOVA, analysis of covariance; BNP, plasma brain natriuretic peptide concentration; BUN, blood urea nitrogen; HbA1c, glycated haemoglobin; HDL-C, high-density lipoprotein cholesterol; LDL-C, low-density lipoprotein cholesterol; UACR, urinary albumin to creatine ratio; $8-\mathrm{OHdG} / \mathrm{Cr}$, urinary 8-hydroxydeoxyguanosine to creatine ratio.

change in UACR more than a combination of aliskiren and a CCB in patients with type 2 diabetes. ${ }^{20} \mathrm{~A}$ substudy of the Aliskiren Trial in Type 2 Diabetes Using Cardiorenal Endpoints (ALTITUDE) trial showed that aliskiren in addition to ACE inhibitor or ARB delayed progression to microalbuminuria and macroalbuminuria in diabetes mellitus, ${ }^{22}$ and another study showed that a combination of an ARB and a diuretic decreased UACR significantly more than a combination of an ARB and a CCB..$^{23}$ Given that almost $90 \%$ of our cohort did not have a diagnosis of diabetes, a combination of aliskiren and an ARB may afford a degree of renal protection in patients with hypertension without diabetes. Nevertheless, further larger studies to evaluate the potential renoprotective effect of a combination of aliskiren and an ARB in non-diabetic patients are warranted.

One patient in our cohort discontinued our study because of hypotension. In the ALTITUDE trial, the incidence of hypotension in those treated with aliskiren and an RAS blocker was $12.1 \%$. Clinicians should be aware of the risk of hypotension with this drug combination. Hyperkalaemia, which was the most common adverse event in the ALTITUDE trial, was not observed in our study. This could also be explained by the low incidence of diabetes mellitus in our cohort. The adverse events associated with aliskiren-RAS blocker combination therapy have not yet been fully elucidated; further studies are required to clarify this issue.

Our study had several limitations. First, it had a relatively small sample size, which may limit the generalisability of our findings. A larger study, preferably with a double-blind, multicentre design, will be required to confirm our findings. Second, the primary end point of this study was change in AI, not the incidence of subsequent cardiovascular events. Nevertheless, our data support previous studies showing the critical relationship between AI and cardiovascular mortality. ${ }^{4}$ Third, we used AI derived from the radial artery as a surrogate of the central AI, which is quantified from central or carotid pulse tracings. The clinical implications of central AI are well established, ${ }^{4}$ but recent studies have also illuminated the relationship between radial AI and cardiovascular risk factors. ${ }^{24}{ }^{25}$ Furthermore, analysis of the radial pulse waveform is a more straightforward technique that could be used as part of routine clinical practice.

In conclusion, combination treatment with aliskiren and valsartan reduced AI to a similar extent as combination therapy with trichlormethiazide and valsartan. The urinary $8-\mathrm{OHdG} / \mathrm{Cr}$ ratio in the valsartan and aliskiren group fell significantly more than the trichlormethiazide group over the course of the study. These findings suggest that in patients with essential hypertension, combination therapy with aliskiren and an ARB may have a therapeutic benefit on central haemodynamic status and might also act to reduce oxidative stress. Further, large prospective studies are needed to clarify the differential contribution of various antihypertensive combination therapies to the reduction of AI.

\section{Author Affiliations}

${ }^{1}$ Department of Cardiovascular Medicine, Okayama University Graduate School of Medicine, Dentistry and Pharmaceutical Sciences, Okayama, Japan ${ }^{2}$ Department of Cardiology, Okayama Heart Clinic, Okayama, Japan ${ }^{3}$ Department of Cardiology, Iwakuni Medical Center, Iwakuni, Japan ${ }^{4}$ Department of Cardiology, Kagawa Prefectural Central Hospital, Takamatsu, Japan ${ }^{5}$ Department of Cardiology, Okayama Rosai Hospital, Okayama, Japan ${ }^{6}$ Department of Cardiology, Saiseikai Imabari Hospital, Imabari, Japan ${ }^{7}$ Department of Cardiology, Yashima General Hospital, Takamatsu, Japan ${ }^{8}$ Department of Cardiology, Tsuyama Chuo Hospital, Tsuyama, Japan ${ }^{9}$ Department of Cardiology, Fukuyama Medical Center, Fukuyama, Japan

Acknowledgements We thank Dr Tadahisa Uesugi (Department of Cardiology, Sumitomo Besshi Hospital, Niihama, Japan), Dr Hirohiko Asonuma (Department of Cardiology, Kasaoka Daiichi Hospital, Kasaoka, Japan) and Dr Kohichi Sakane (Department of Cardiology, Okayama City General Medical Center, Okayama, Japan) for recruiting participants to this study.

Funding This study was funded by the Okayama Medical Foundation.

Competing interests TM has received an honorarium and a scholarship from Novartis Pharmaceutical Co and an honorarium from Fukuda Denshi. HI has received an honorarium and a scholarship from Novartis Pharmaceutical. The other authors have no conflicts of interest in relation to the materials presented in this article.

Provenance and peer review Not commissioned; externally peer reviewed. 
Open Access This is an Open Access article distributed in accordance with the Creative Commons Attribution Non Commercial (CC BY-NC 4.0) license, which permits others to distribute, remix, adapt, build upon this work non-commercially, and license their derivative works on different terms, provided the original work is properly cited and the use is non-commercial. See: http://creativecommons.org/licenses/by-nc/4.0

(c) Article author(s) (or their employer(s) unless otherwise stated in the text of the article) 2017. All rights reserved. No commercial use is permitted unless otherwise expressly granted.

\section{REFERENCES}

1. Murgo JP, Westerhof N, Giolma JP, et al. Aortic input impedance in normal man: relationship to pressure wave forms. Circulation 1980;62:105-16.

2. Mitchell GF, Parise $H$, Benjamin EJ, et al. Changes in arterial stiffness and wave reflection with advancing age in healthy men and women: the framingham heart study. Hypertension 2004;43:1239-45.

3. Oliver JJ, Webb DJ. Noninvasive assessment of arterial stiffness and risk of atherosclerotic events. Arterioscler Thromb Vasc Bio 2003;23:554-66.

4. Williams B, Lacy PS, Thurston $\mathrm{H}$, et al. Response to letters regarding article, "differential impact of blood pressure-lowering drugs on central aortic pressure and clinical outcomes: principal results of the conduit artery function evaluation (CAFE) study". Circulation 2006; 114:e540-e541.

5. Guérin AP, Pannier B, Métivier F, et al. Assessment and significance of arterial stiffness in patients with chronic kidney disease. Curr Opin Nephrol Hypertens 2008;17:635-41.

6. Jiang XJ, O'Rourke MF, Zhang YQ, et al. Superior effect of an angiotensin-converting enzyme inhibitor over a diuretic for reducing aortic systolic pressure. J Hypertens 2007;25:1095-9.

7. Morgan T, Lauri J, Bertram D, et al. Effect of different antihypertensive drug classes on central aortic pressure. Am J Hypertens 2004;17:118-23.

8. Matsui Y, Eguchi K, O'Rourke MF, et al. Differential effects between a calcium channel blocker and a diuretic when used in combination with angiotensin II receptor blocker on central aortic pressure in hypertensive patients. Hypertension 2009;54:716-23.

9. Doi M, Miyoshi T, Hirohata S, et al. Combination therapy of calcium channel blocker and angiotensin II receptor blocker reduces augmentation index in hypertensive patients. Am J Med Sci 2010;339:433-9.

10. Nussberger J, Wuerzner G, Jensen C, et al. Angiotensin II suppression in humans by the orally active renin inhibitor aliskiren (SPP100): comparison with enalapril. Hypertension 2002;39:e1-8.

11. Ogihara T, Kikuchi K, Matsuoka H, et al. The Japanese society of hypertension guidelines for the management of hypertension (JSH 2009). Hypertens Res 2009;32:318-107.
12. Kaji Y, Miyoshi T, Doi M, et al. Augmentation index is associated with B-type natriuretic peptide in patients with paroxysmal atrial fibrillation. Hypertens Res 2009;32:611-6.

13. Miyoshi T, Doi M, Noda Y, et al. Arterial stiffness determined according to the cardio-ankle vascular index is associated with paroxysmal atrial fibrillation: a cross-sectional study. Heart Asia 2014:6:59-63.

14. Miyoshi T, Ito $\mathrm{H}$. Assessment of arterial stiffness using the cardioankle vascular index. Pulse 2016;4:11-23.

15. Shirai K, Utino J, Otsuka K, et al. A novel blood pressureindependent arterial wall stiffness parameter; cardio-ankle vascular index (CAVI). J Atheroscler Thromb 2006;13:101-7.

16. Yamanaka T, Kawai $\mathrm{Y}$, Miyoshi T, et al. Remote ischemic preconditioning reduces contrast-induced acute kidney injury in patients with ST-elevation myocardial infarction: a randomized controlled trial. Int J Cardiol 2015;178:136-41.

17. Schneider MP, Delles C, Klingbeil AU, et al. Effect of angiotensin receptor blockade on central haemodynamics in essential hypertension: results of a randomised trial. J Renin Angiotensin Aldosterone Syst 2008:9:49-56.

18. Moniwa N, Varagic J, Ahmad S, et al. Hemodynamic and hormonal changes to dual renin-angiotensin system inhibition in experimental hypertension. Hypertension 2013;61:417-24.

19. Ferrario CM, Varagic J. The ANG-(1-7)/ACE2/mas axis in the regulation of nephron function. Am J Physiol Renal Physiol 2010;298:F1297-305.

20. Abe M, Maruyama N, Suzuki H, et al. Additive renoprotective effects of aliskiren on angiotensin receptor blocker and calcium channel blocker treatments for type 2 diabetic patients with albuminuria. Hypertens Res 2012;35:874-81.

21. Renke M, Lizakowski S, Tylicki L, et al. Aliskiren attenuates oxidative stress and improves tubular status in non-diabetic patients with chronic kidney disease-placebo controlled, randomized, cross-over study. Adv Med Sci 2014;59:256-60.

22. Heerspink HJ, Persson F, Brenner BM, et al. Renal outcomes with aliskiren in patients with type 2 diabetes: a prespecified secondary analysis of the ALTITUDE randomised controlled trial. Lancet Diabetes Endocrinol 2016;4:309-17.

23. Matsui $\mathrm{Y}$, Eguchi K, Ishikawa J, et al. Urinary albumin excretion during angiotensin II receptor blockade: comparison of combination treatment with a diuretic or a calcium-channel blocker. Am J Hypertens 2011;24:466-73.

24. Shinohata R, Nakatsu T, Yuki Y, et al. Association of augmentation index of radial pressure wave form with diurnal variation pattern of blood pressure in untreated patients with essential hypertension. $J$ Hypertens 2008;26:535-43.

25. Doi M, Miyoshi T, Hirohata S, et al. Increased augmentation index of the radial pressure waveform in patients with paroxysmal atrial fibrillation. Cardiology 2009;113:138-45. 